\title{
PATOLOGÍA CERVICAL Y EL REPORTE DE ASCUS EN LA CITOLOGÍA
}

\author{
CERVICAL PATHOLOGY AND REPORTING OF \\ ATYPICAL SQUAMOUS CELLS OF UINDETERMINED \\ SIGNIIFICANCE (ASCUIS) IN CERVICAL CYTOLOGY \\ Mario Arturo González Mariño, M.D." \\ Recibido: octubre 10/ 2002 - Revisado: mayo 19/2003 - Aceptado: junio 19/2003
}

\section{RESUMEN}

Objetivos: Determinar la frecuencia de citología con reporte de ASCUS (Atypical Squamus Cells of Undetermined Significance) en pacientes cuya biopsia es compatible con neoplasia intraepitelial o carcinoma invasivo de cérvix, y evaluar algunas características personales y clínicas de estas pacientes atendidas en la Liga Contra el Cáncer. Bogotá, Colombia.

Metodología: Estudio observacional del tipo serie de casos. En los informes emitidos entre enero 1 y junio 30 de 2000 por la sección de patología de la Liga Contra el Cáncer, se revisaron los reportes de citología con diagnóstico de: atipias coilocíticas, condiloma, NIC I, II, III o carcinoma invasivo. Fueron seleccionadas para análisis aquellas reportadas como ASCUS. Como base de datos se usó el programa EPI INFO.

Resultados: De las 374 biopsias estudiadas, hubo 51 (13.6\%) con reporte citológico de ASCUS. El análisis patológico reveló atipias coilocíticas o condiloma en 31 casos, NIC(neoplasia intraepitelial cervical) I en diez, NIC II-III en nueve y sugestivo de Carcinoma Adenoescamoso en una. En ocho de ellas, se encontraron antecedentes de tratamientos previos por patología cervical. En los ca-

Médico Ginecólogo Oncólogo. e-mail: marioar90@hotmail.com sos en los cuales se incluyó en el informe de citología una observación sobre la posible relación de los hallazgos con un diagnóstico histológico, hubo seis en las que se sugirió la existencia de una lesión por virus del papiloma humano pero en dos de ellas el reporte de biopsia fue neoplasia intraepitelial de alto grado. Se presentan datos personales y clínicos del grupo analizado.

Conclusiones: La citología ASCUS involucra desde cambios benignos, que son la mayoría, hasta neoplasia, por lo cual su reporte no debe desestimarse. Las actuales recomendaciones emitididas con la clasificación de Bethesda 2001 posiblemente seleccionen mejor al grupo de pacientes que puede albergar un carcinoma y requiere un manejo activo. Se requiere de nuevos estudios que evaluen la utilidad de esta nueva clasificación

Palabras clave: ASCUS, citología, cérvix.

\section{SUMMARY}

Objective: To evaluate the relationship between the cervical pathology and the report of ASCUS (Atypical Squamus Cells of Undetermined Significance) pap in patients from the Liga Contra el Cáncer. Bogotá, Colombia. 
Methods: This is an observational study of the type of case report. The ASCUS pap smear in the cytologic report of patients with a pathologic diagnosis of coilocitic atypia, condyloma, cervical intraepithelial neoplasia (CIN) I,II,III or invasive carcinoma was choiced to make the analysis by using the EPI INFO program.

Results: The ASCUS pap were found in $51(13.6 \%)$ out of the 374 pathologic reports selected to be analyzed. In 8 patients previous cervical treatments were undertaken. The biopsy report was coilocytic atypia or condiloma in 31 women, CIN I in 10, CIN II-III in 9 and a biopsy suggestive of adenosquamous neoplasm. An additional information favored a human papilloma lesion in 6 pap reports but a high grade intraepitelial neoplasm was found in two biopsies. Personal and clinical information is shown.

Conclusions: The ASCUS pap involve a range from benign alterations, which are the majority, as well as the possibility of finding a neoplasm so that its report should no be underestimated. The Bethesda 2001 recommendations should select the patients needed of an active treatment. New research is needed on the utility of this classification.

Key words: ASCUS, cytology, cervix

\section{INTRODUCCIÓN}

El reporte de atipias escamosas de significado indeterminado (ASCUS) surgió en la clasificación de Bethesda debido a la necesidad de disminuir el reporte de atipias ${ }^{1}$ en la clasificación de Papanicolaou.

Se definen como ASCUS aquellas anomalías celulares más marcadas que las atribuibles a cambios reactivos pero que cuantitativa o cualitativamente no llenan los criterios para el diagnóstico de lesión intraepitelial escamosa. Los cambios celulares en la categoría ASCUS pueden reflejar un cambio benigno exuberante o una lesión potencialmente seria que no es posible clasificar con seguridad. Tam- bién incluye los cambios citológicos altamente anormales, pero en los cuales solamente se observan una o dos células diagnósticas (cuantitativamente insuficientes para hacer un diagnóstico de alto grado). ${ }^{2}$

El pronóstico de las pacientes con citología ASCUS depende del grado de anormalidad observado en el cérvix, que abarca tanto procesos inflamatorios cuyo curso será benigno, como lesiones de alto grado e invasivas. ${ }^{2}$ Entre 10 y $20 \%$ pueden encontrarse NIC II y III, y carcinoma invasivo en uno de cada mil reportes. ${ }^{3}$

El objetivo del presente trabajo es conocer la frecuencia de ASCUS en una institución dedicada al diagnóstico de enfermedad oncológica en Bogotá, Colombia.

\section{MATERIALES Y MÉTODOS}

Estudio observacional del tipo serie de casos. En los informes emitidos entre enero $1 \mathrm{y}$ junio 30 de 2000 por la sección de patología de la Liga Contra el Cáncer, se revisaron los reportes de citología con diagnóstico de: atipias coilocíticas, condiloma, NIC I, II, III o carcinoma invasivo. De estas, se separaron para el análisis las citologías reportadas como ASCUS. El programa EPI INFO versión 6,04 d se usó como base de datos.

\section{RESULTADOS}

Durante el período de estudio de enero 1 a junio 30 de 2000 se reportaron 374 biopsias con alguno de los siguientes diagnósticos: atipias coilocíticas, condiloma, NIC (I, II, III) o carcinoma invasivo. Para el análisis fueron seleccionados $51(13,6 \%)$ registros, cuya citología fue informada como ASCUS.

Edad: El rango de edad se encontró entre 24 y 71 años, con una media de 35,9 y moda de 30 años (7 pacientes). 
Paridad: La mayoría de las pacientes tenían entre 1 y 3 hijos (70\%) (tabla 1).

Compañeros sexuales: Se registraron datos en 35 pacientes, $13(37,1 \%)$ reportaron un compañero sexual, dos a tres compañeros en $16(45,7 \%)$ mujeres y de cuatro a seis en 6 de ellas $(17,1 \%)$. (tabla 2).

Patología Cervical previa: Ocho pacientes recibieron tratamientos previos por patología cervical (tabla 3).

En la colposcopia los hallazgos más frecuentes fueron: epitelio acetoblanco en 22 mujeres, leucoplasia en seis y metaplasia en cuatro. En 10 pacientes la colposcopia se consideró insatisfactoria.

En la mayoría de las biopsias con citología de ASCUS se encontraron atipias coilocíticas o condiloma (60\%). Uno de los casos era sugestivo de carcinoma adenoescamoso y fue remitido para completar su evaluación (tabla 4).

Al relacionar los hallazgos de epitelio acetoblanco con el resultado de la biopsia, se encontraron atipias coilocíticas o condiloma en 12 pacientes, NIC I en cinco y NIC de alto grado en cinco más.

Junto con el diagnóstico de ASCUS, en 12 casos se consideró una posible relación causal. En seis informes el patólogo sugirió una lesión por virus del papiloma humano, hallazgo que coincidió con el resultado de la biopsia en cuatro oportunidades. En los dos restantes la biopsia reportó una neoplasia intraepitelial de alto grado. Una de las citologías era sugestiva de proceso reparativo, pero el diagnóstico histológico fue condiloma. Por último, cuatro casos cuya apariencia sugería NIC resultaron ser condilomas.

En las 47 pacientes con registro de tratamiento se observó que el Acido tricloroacético predominó sobre los diversos esquemas terapéuti-
Tabla 1. Distribución de las pacientes con reporte citológico de ASCUS según la paridad

\begin{tabular}{ccc} 
Paridad & $\begin{array}{c}\text { Número } \\
\text { de pacientes }\end{array}$ & $\%$ \\
\hline 0 & 7 & 13,7 \\
\hline 1 a 3 & 35 & 68,6 \\
\hline 4 y más & 9 & 17,6 \\
\hline
\end{tabular}

Tabla 2. Distribución de las pacientes con reporte citológico de ASCUS según el número de compañeros sexuales

\begin{tabular}{ccc}
$\begin{array}{c}\text { Numero de } \\
\text { compañeros } \\
\text { sexuales }\end{array}$ & $\begin{array}{c}\text { Número } \\
\text { de pacientes }\end{array}$ & $\%$ \\
\hline 1 & 13 & 37,4 \\
\hline 2 a 3 & 16 & 45,7 \\
\hline 4 a 6 & 6 & 17,4 \\
\hline
\end{tabular}

cos que se emplearon en las lesiones de bajo grado (tabla 5).

\section{DISCUSIÓN}

En la clasificación de Bethesda de 1988 se aprobaron varios cambios, uno de los cuales fue reemplazar la antigua clase II (atipia) por la de "cambios reactivos o reparativos". En ésta quedaron incluídos los cambios inflamatorios, terapéuticos y otros efectos que alteran los hallazgos celulares pero no son cáncer.

\begin{tabular}{|c|c|c|}
\hline Diagnóstico & $\begin{array}{c}\text { Tratamiento } \\
\text { previo de pacientes }\end{array}$ & Número \\
\hline NIC alto grado & Lletz & 2 \\
\hline NIC alto grado & Conización & 1 \\
\hline NIC bajo grado & Acido tricloroacético & 2 \\
\hline NIC bajo grado & 5-fluorouracilo & 1 \\
\hline NIC bajo grado & Lletz & 1 \\
\hline NIC bajo grado & Crioterapia & 1 \\
\hline
\end{tabular}


Tabla 4. Distribución de las pacientes con reporte citológico de ASCUS según el diagnóstico histológico

\begin{tabular}{lc}
\multicolumn{1}{c}{ Diagnóstico } & \multicolumn{1}{c}{$\begin{array}{c}\text { Número } \\
\text { de pacientes }\end{array}$} \\
\hline $\begin{array}{l}\text { Atipias coilocíticas } \\
\text { o condiloma }\end{array}$ & 31 \\
\hline NIC I & 10 \\
\hline NIC II-III & 9 \\
\hline Sugestivo de Carcinoma & 1 \\
\hline Adenoescamoso & \\
\hline
\end{tabular}

Los cambios celulares más severos (o inciertos de NIC) se incluyeron en la categoría de "Anormalidad de células epiteliales escamosas", que incluye a las atipias escamosas de significado indeterminado y las lesiones intraepiteliales escamosas (que a su vez comprenden todas las lesiones HPV y /o NIC, y el carcinoma escamoso). ${ }^{4}$

El reporte de ASCUS surgió por dificultad que había para incluir ciertos hallazgos dentro de alguno de los grupos establecidos, pero que podían estar asociados con cambios reparativos, inflamación, NIC o carcinoma invasivo. De ahí que su informe no puede ser despreciado y obliga a una evaluación complementaria.

La recomendación de incluir un comentario sobre la posible conexión con determinada patología, pretende alcanzar una mejor aproximación al diagnóstico definitivo.

En el reporte de ASCUS también se pueden encontrar causas como mala fijación, que puede ocasionar dificultad en el diagnóstico. ${ }^{5}$

La variabilidad entre los laboratorios es tal, que algunos presenten cifras hasta de 20\% de citologías ASCUS. ${ }^{1} \mathrm{Al}$ respecto, las guías del Instituto Nacional de Cáncer(U.S.A) afirma que sólo 5\% o menos de las citologías emitidas por un laboratorio deberían tener este diagnóstico. Así mismo, en poblaciones de alto riesgo, la proporción debería ser inferior a 2-3 veces al informe de lesión intraepitelial escamosa. ${ }^{6}$

En una revisión de 19 trabajos que incluyeron 6892 reportes de ASCUS en citologías de tamizaje, se hallaron 530 lesiones intraepiteliales de alto grado $(7,7 \%$, con un rango de $2,6-12,9 \%)$ y la frecuencia de carcinoma invasivo fue de 0,07 \% (rango de 0\%-3,8\%). ${ }^{1}$ En el trabajo de Lachman y cols ${ }^{7}$, de 560 biopsias en pacientes con ASCUS, $357(63,8 \%)$ fueron benignas o reactivas, 109 $(19,5 \%)$ lesiones de bajo grado y $94(16,8 \%)$ de

Tabla 5. Distribución de las pacientes con reporte citológico de ASCUS según el diagnóstico histológico y el tratamiento

\begin{tabular}{lcl} 
Diagnóstico & $\begin{array}{c}\text { Número de } \\
\text { pacientes }\end{array}$ & Tratamiento \\
\hline Atipias coilocíticas & 19 & ATA \\
o condiloma & 5 & Crioterapia \\
& 5 & Observación \\
& 1 & 5-Floururacilo \\
& 1 & Electrofulguración \\
\hline NIC I & 5 & Lletz \\
& 1 & 5-Floururacilo \\
& 1 & Se remitió \\
\hline NIC de alto grado & 7 & Lletz \\
& 1 & Se remitió \\
\hline Sugestivo de carcinoma & 1 & Se remitió \\
adenoescamoso & & \\
\hline
\end{tabular}

alto grado, porcentaje muy superior al encontrado por Alanen de $3,9 \%{ }^{8}$

Dentro de las opciones de manejo se encuentran varias posibilidades: repetir la citología cuatro a seis meses más tarde, tratar la infección si existe, tomar una nueva muestra, identificar la presencia del virus del papiloma humano o practicar una colposcopia.,

Para la decisión terapéutica se debe tener en cuenta que dicha alteración tiene una alta probabilidad de regresión a la norma- 
lidad o hacia cambios celulares benignos. En el trabajo ya mencionado de Alanen, después de 2 años de seguimiento esta regresión fue de $78,6 \%$, pero antes de mostrar cambios normales o benignos en la citología hubo anormalidad persistente por más de 12 meses en el $15 \%$ de ellas. ${ }^{8}$

Aunque en la actualidad se acepta la clasificación histopatológica propuesta por Richart, ${ }^{10}$ quien divide las neoplasias intraepiteliales en dos categorías: la de bajo grado que incorpora los condilomas y los NIC I, y la de grado alto donde se encuentran los NIC II y III, para la fecha del estudio todavía no se había incorporado este sistema dentro de la institución.

Para la orientación terapeútica inicial de estas lesiones se puede seguir la recomendación de Lachman. ${ }^{7}$ Si la apariencia de las lesiones orienta hacia el diagnóstico de displasia, se pueden enfocar como una lesión intraepitelial de bajo grado, pero aquellas consideradas como reactivas se pueden tratar en forma conservadora. Es de anotar, que la nueva clasificación de Bethesda en el 2001 acordó eliminar esta última categoría, para que los patólogos traten de incluir tales casos como "negativa para lesión intraepitelial o malignidad". En el caso de hallazgo "células escamosas atípicas" esta nueva clasificación la dividió en citologías de significado indeterminado (ASC-US) y en las que no se puede descartar una lesión escamosa intraepitelial de alto grado (ASC-H). ${ }^{11}$

La variedad de tratamientos que se encontraron en este estudio para lesiones de bajo grado es llamativa, pues está en contra de los informes de la literatura que revelan una alta frecuencia de regresión espontánea. Por tal motivo se recomienda observación y solamente actuar en caso de persistencia. ${ }^{12,13,14}$

\section{CONCLUSIONES}

La citología ASCUS involucra desde cambios benignos hasta diagnóstico de cáncer, por lo cual nunca debe desestimarse su valor. Las recomen- daciones actuales, emitidas con la clasificación de Bethesda de 2001 posiblemente seleccionen mejor al grupo de pacientes que puede albergar un carcinoma y requiere por lo tanto un manejo activo. No obstante, son necesarios nuevos estudios que permitan evaluar la utilidad de esta nueva clasificación.

\section{BIBLIOGRAFÍA}

1. Bernard-Pearl L, Smith-McCune K. Controversies in the Management of ASCUS and AGCUS: Two very different beasts. Curr Probl Obstet Gynecol Fertil $2001 ; 24: 7-23$

2. Jones HW. Clinical treatment of women with atypical squamous cells of undetermined significance or atypical glandular cells of undetermined significance cervical cytology 2000;43:381-393

3. Solomon D, Schiffman M, Tarone R, for the ALTS group. Comparison in three management strategies for patients with atypical squamous cells of undermined significance: baseline results from a randomized trial. J Natl Cancer Inst. 2001;93:293299

4. Wilkinson EJ. Pap smears and screening for cervical neoplasia. Clinical Obstetrics and Gynecology 1990;33:817-825

5. Solomon D, Frable WJ, Vooijs GP, Wilbur DC et al. ASCUS and AGUS criteria. Acta Cytologica 1998;42:16-24.

6. Kurman RJ, Henson DE, Herbst AL, Noller KL, Schiffman M. Interim guidelines for management of abnormal cervical cytology. JAMA 1994;271: 18669

7. Lachman M F, Cavallo- Calvanese C. Qualification of atypical squamous cells of undetermined significance in an independent laboratory: is it useful or significant? Am J Obstet Gynecol 1998;179:421-9

8. Alanen KW, Elit LM, Molinaro PA, McLachlin CM. Assessment of cytologic follow-up as the recommended management for patients with atypical squamous cells of undetermined significance or low grade squamous intraepithelial lesions. Cancer (Cancer Cytopathol) 1998;84:5-10

9. Janicek MF, Averette HE. Cervical cancer : Prevention, Diagnosis and Therapeutics. CA Cancer J Clin 2001;51:92:114 
10. Richart RM. A modified terminology for cervical intraepithelial neoplasia. Obstet Gynecol 1990;75:131-133.

11. Solomon D, Davey D, Kurman R et al. The 2001 Bethesda System. Terminology for reporting results of cervical cytology. JAMA 2002, 287: 2114-2119

12. Montz FJ. Management of high-grade cervical intraepithelial neoplasia and low-grade squamous intraepithelial lesion and potential complications.
Clinical Obstetrics and Gynecology 2000;43:395-409

13. Kaufman RH, Adam E, Vonka V. Human papillomavirus infection and cervical carcinoma. Clinical Obstetrics and Gynecology 2000;43:363-378

14.Austoker J. Cancer Prevention in Primary Care: Screening for cervical cancer. BMJ 1994;309:241248 